\title{
The relationship between patient satisfaction and functional status in inpatient rehabilitation: a comparison over time
}

\begin{abstract}
Introduction: The purpose of this study was to compare patient satisfaction over time in the context of major changes in service delivery in acute rehabilitation (sicker patients admitted earlier and staying fewer days). We hypothesized that patient satisfaction is significantly correlated with patient functional goal achievement

Methods: Data was collected on two cohorts: Patients receiving inpatient rehabilitation for at least two weeks at a University Hospital during a two year period (Group A, $\mathrm{n}=210$ ) or a second two year period (Group B, $\mathrm{n}=280$ ). Patient progress is measured with the Functional Independence Measure (FIM) in areas A thru M at admission, discharge, and goals established at admission. Patients are considered to have met their goals if their discharge FIM score is within 10 points of their predicted goal. Three months post discharge all patients were contacted by telephone interview about their satisfaction with their rehabilitation.

Results: Two hundred and four in Group A patients reported satisfaction, but only 185 met their FIM goals. Of the six who reported dissatisfaction, three met their FIM goals. Two hundred and sixty eight Group B patients reported satisfaction, and 251 met their FIM goals of the 12 who reported dissatisfaction, 10 met their FIM goals. The average length of stay for Group A was three times longer than Group B. Chi Square analyses of the differences between satisfied and dissatisfied patients in the two groups was significant for Group A $(\mathrm{p}<.01)$, meaning satisfaction correlated with functional goal achievement. There is no correlation between functional achievement and satisfaction for Group B. Medical complications were noted to be higher in Group B.

Conclusion: Current trends in rehabilitation as in Group B patients (sicker patients admitted earlier and staying fewer days) have not affected patient satisfaction. There was a correlation between functional goal attainment and patient satisfaction in Group A but not with Group B.
\end{abstract}

Keywords: patient satisfaction, rehabilitation
Volume 3 Issue 6 - 2018

\author{
Kanakadurga R Poduri, Marcia Scherer \\ Department of Physical and Rehabilitation Medicine, University \\ of Rochester Medical Center, USA
}

\begin{abstract}
Correspondence: Kanakadurga R Poduri, Department of Physical and Rehabilitation Medicine, University of Rochester Medical Center, Tel (585)208-0629,
\end{abstract}

Email KR_Podure@urmc.rochester.edu

Received: November 03, 2018 | Published: November 26, 2018

\section{Introduction}

Patient perceptions of their health status may or may not correlate highly with functional ratings of their capabilities. This may be further complicated by the fact that in rehabilitation medicine, clinicians often are concerned with such subjective conditions as pain and fatigue. Patients may report satisfaction if they make functional gains, but satisfaction may also depend upon other factors, including psychosocial and personal characteristics that may also play an important role in achieving the goals of rehabilitation. ${ }^{1-3}$ Perceived characteristics of the rehabilitation unit's environment may additionally contribute to patient dissatisfaction as well as, for example, dysfunctional family dynamics and substance abuse. It is also the case that clinician and patient perspectives can differ. For example, Cushman and Scherer documented discrepancies in perceptions between therapists and consumers regarding utility and aesthetic aspects of prescribed assistive devices. Scherer, ${ }^{4}$ has also demonstrated that patient and therapist judgments of what constitutes successful rehabilitation also vary significantly. Similarly, Lewinter \& Mikkelsen $^{5,6}$ separately interviewed both therapists and patients in an experimental stroke unit about the rehabilitation process after stroke and the focus of the comments was entirely different for the two groups.
Fairclough, ${ }^{7}$ notes that while physiological responses may be the optimal endpoint for assessing treatment/intervention outcomes, it is important to assess and address whether functional outcomes make a noticeable difference to the patient. Thus, in rehabilitation medicine, patient reported outcomes (PROs) are crucial to evaluate.

PROs can range from the reporting of the frequency and severity of symptoms, the impact of disease and its treatment on the physical, functional, social and emotional well-being of an individual to satisfaction with health care delivery. ${ }^{?}$

PROs have been obtained from Chart Reviews. Chart reviews have been defined as retrospective study of existing data that was originally recorded for reasons other than research and uses the medical record as the primary data source. ${ }^{8}$ While disadvantages and weaknesses have been noted, ${ }^{9,10}$ the advantage of the chart review is that it allows the comparison of data over long periods. With the increasing focus on randomized control trials, however, chart reviews have become undervalued in spite of their methodological advantages for epidemiological, quality and outcome assessment studies. ${ }^{11}$

Organizational trends in inpatient rehabilitation are important to understand. Over time, patient lengths of stay (LOS) in inpatient rehabilitation facilities (IRF) have decreased substantially since 
1994. ${ }^{12}$ Mallinson etal. ${ }^{13}$ Ottenbacher et al. ${ }^{12}$ found that decreasing LOS did not result in significant changes in functional status nor in living situation, which, may be due to improved clinical efficiency and intensity of rehabilitation services. However, neither of the above studies addressed decreasing LOS on patient satisfaction. In the current study, changes in patient satisfaction over similar timeframe was addressed in light of decreasing LOS. Over two periods in time and patients were surveyed over the phone about their follow-up medical and functional status, psychosocial status and overall satisfaction with their rehabilitation stay such that they would recommend it to others. The study hypothesis was that patient satisfaction would correlate well with the progress they made as reflected on the FIM scores. Another hypothesis was that less satisfaction and functional gain would be reported in the second cohort compared to the first cohort due to shorter lengths of stay for the former. ${ }^{14,15}$

\section{Methods}

This two-group retrospective study analyzed data from the charts of 210 individuals admitted to the acute rehabilitation unit in Strong Memorial Hospital (Rochester, NY) over a period of two years (Group A) and a few years later, another group for two years of 280 patients admitted to the acute rehabilitation unit (Group B). The staff being the same treating both the groups except CMS rules have changed over the course of time.

\section{Procedures}

Subjects were surveyed on their satisfaction as a measure of quality assurance. All patients included in the study had stayed on the unit for at least two weeks. The unit routinely uses the Med Tel Outcomes survey as a quality assessment measure. Med Tel Outcomes (www.medteloutcomes.com) provides subscribing rehabilitation facilities with information that is gathered to manage their outcomes and to facilitate compliance with Commission on Accreditation of Rehabilitation Facilities (CARF) standards. Strong Memorial Hospital contracts with Med Tel Outcomes to monitor the satisfaction and function of patients post-discharge. Med Tel results also provide a method to compare outcomes with a national model.

This Med Tel telephone survey is conducted three months after discharge. The Med Tel questions are in Appendix 1.

Additionally, the functional status for each patient was measured on admission and at discharge, using the Functional Independence Measure (FIM). The staff established discharge goals during the first week of rehabilitation admission. For the purposes of this study, patients were considered to have met their goals if the discharge FIM score was within 10 points from the predicted discharge goal.

\section{Results}

In the first cohort (Group A), 210 patients were surveyed, of whom 204 reported overall satisfaction and six reported being dissatisfied. Of the 210 patients, 185 were considered to have met the FIM discharge goals and 25 did not achieve their predicted goals. Of the 185 who achieved their predicted goals, 182 (98\%) reported being satisfied with their acute rehabilitation stay. Of the 25 not meeting the predicted goals, $22(88 \%)$ were satisfied. The difference between these percentages is statistically significant $(\mathrm{Z}=8.47, \mathrm{p}<.00001)$. ChiSquare analyses of the differences between satisfied and dissatisfied patients indicate that overall satisfaction with an acute rehabilitation stay is correlated with achievement of predicted functional goal (Table 1) (Figures 1).

Table I Demographics of participants

\begin{tabular}{|c|c|c|c|c|}
\hline & $\begin{array}{l}\text { Satisfied group } \\
\text { A }(n=204)\end{array}$ & Satisfied group $B(n=268)$ & Dissatisfied group A $(n=6)$ & $\begin{array}{l}\text { Dissatisfied group } \\
\text { B }(n=\mid 2)\end{array}$ \\
\hline \multicolumn{5}{|c|}{ Age (in years) } \\
\hline Mean & 58 & 60 & 29 & 63 \\
\hline Range & $13-92$ & Dec-91 & $21-36$ & $48-77$ \\
\hline \multicolumn{5}{|l|}{ Sex } \\
\hline Male & 114 & 156 & 6 & 7 \\
\hline Female & 90 & 112 & 0 & 5 \\
\hline \multicolumn{5}{|c|}{ Diagnosis } \\
\hline CVA & 87 & 63 & 0 & 4 \\
\hline $\mathrm{SCl}$ & 65 & 33 & 6 & 3 \\
\hline Others & 58 & 172 & 0 & 5 \\
\hline
\end{tabular}

In the second cohort (Group B), 280 patients were surveyed. Out of this total 268 patients reported satisfaction and 251 (94\%) met their FIM goals. Of the 12 who reported dissatisfaction, 10 met their FIM goals $(83 \%)$. Chi-Square analyses of the differences between satisfied and dissatisfied patients indicate that overall satisfaction with an acute rehabilitation stay was not significantly correlated with achievement of predicted functional goals (Table 1) (Figures 1). When comparing the two cohorts, the average length of stay for Group A was three times longer than for Group B. Chi-Square analyses of the differences between satisfied and dissatisfied patients in the two groups was significant for Group A $(\mathrm{p}<.01)$, meaning satisfaction correlated with functional goal achievement. There is no correlation between functional goal achievement and satisfaction for Group B. Medical complications were noted to be higher in Group B. 

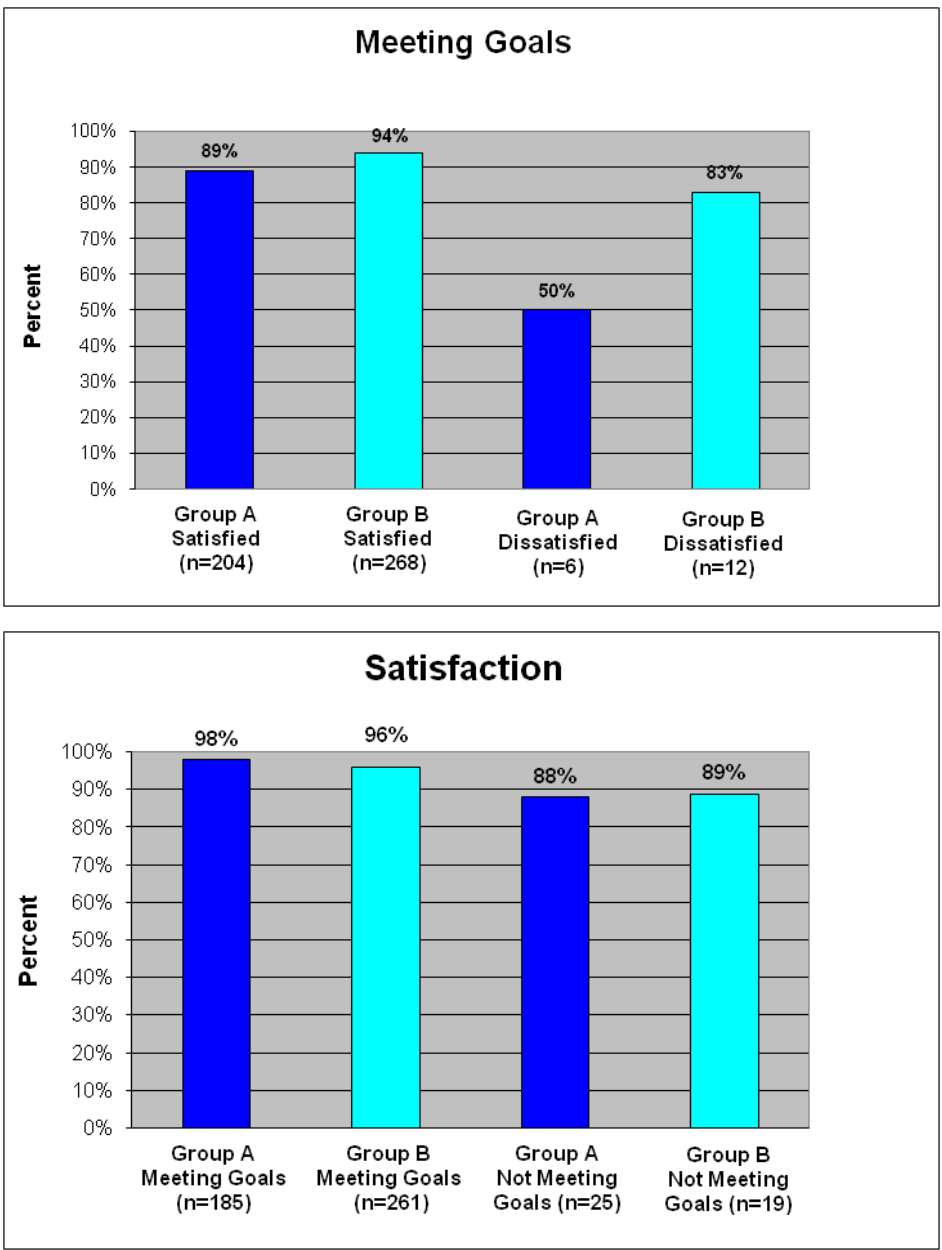

Figures I Outcomes for group A and the group B participants.

Table 2 Outcomes of group A participants

\begin{tabular}{lllll}
\hline & Satisfied group A $(\mathbf{n}=\mathbf{2 0 4})$ mean & $\begin{array}{l}\text { Satisfied group } \\
\mathbf{B}(\mathbf{n}=\mathbf{2 6 8}) \text { Mean }\end{array}$ & $\begin{array}{l}\text { Dissatisfied group } \\
\mathbf{B}(\mathbf{n}=\mathbf{6}) \text { mean }\end{array}$ & $\begin{array}{l}\text { Dissatisfied group } \\
\mathbf{B}(\mathbf{n}=\mathbf{1 2}) \text { mean }\end{array}$ \\
\hline $\begin{array}{l}\text { Average LOS (days) } \\
\text { Average FIM Scores }\end{array}$ & 38 & 12.54 & 59 & 11.25 \\
$\begin{array}{l}\text { (items A - M) } \\
\text { Achieved }\end{array}$ & 70 & & & \\
Goal & 71 & 97.28 & 34 & 85 \\
\hline
\end{tabular}

\section{Discussion}

Two hypotheses guided this research: (1) patient satisfaction would correlate well with the progress they made as reflected on the FIM scores and (2) less satisfaction and functional gain would be reported in the Group B cohort compared to the Group A cohort due to shorter lengths of stay for the former. This study failed to show that the Group B cohort reported higher satisfaction with higher FIM scores or less satisfaction than the Group A cohort. Those patients who were dissatisfied reported dissatisfaction in spite of achieving higher functional levels. Hence, satisfaction has to be tied to other factors (e.g., medical complications, comorbidities, length of stay etc...).

\section{Conclusion}

Earlier studies have shown that current trends in rehabilitation (sicker patients admitted earlier and staying fewer days) have not affected patient functional outcome and discharge living setting, nor have they negatively affected IRF occupancy. The results of this study indicate decreased LOS has not had a negative effect on 
patient satisfaction. While the results showed a correlation between functional goal attainment and patient satisfaction in Group A (the first cohort), this was not the case for Group B (the second cohort). Why this difference exists requires future research and the inclusion of different variables such as the increased prevalence of obesity as an example.

\section{Acknowledgment}

None.

\section{Conflicts of interest}

The authors declare no conflicts of interest.

\section{References}

1. Arts ML, Kwa VI, Dahmen R. High satisfaction with an individualized stroke care programme after hospitalization of patients with a TIA or minor stroke: a pilot study. Cerebrovasc Dis. 2008;25(6):566-571

2. Davidson AC, Auyeung V, Luff R, et al. Prolonged benefit in post-polio syndrome from comprehensive rehabilitation: A pilot study. Disabil Rehabil. 2009;31(4):309-317.

3. Wain, HR, Kneebone, II \& Billings J. Patient experience of neurologic rehabilitation: A qualitative investigation. Arch Phys Med Rehabil 2008;89(7):1366-1371.

4. Scherer MJ. Living in the state of stuck: How assistive technology impacts the lives of people with disabilities. Cambridge, MA: Brookline Books; 2005.

5. Lewinter M, Mikkelsen S. Therapists and the rehabilitation process after stroke. Disabil Rehabil. 1995;17(5):211-216.
6. Lewinter M, Mikkelsen S. Patients' experience of rehabilitation after stroke. Disabil Rehabil. 1995;17(1):3-9.

7. Fairclough DL. Patient reported outcomes as endpoints in medical research Statistical Methods in Medical Research. 2004;13: 115-138.

8. Hess DR. Retrospective studies and chart reviews. Respiratory Care. 2004;49(10):1171-1174.

9. Ehnfors, M. \& Smedby B. Patient satisfaction surveys subsequent to hospital care: problems of sampling, non-response and other losses. International Journal for Quality in Health Care. 1993;5:19-32.

10. Quintana JM, González N, Bilbao A, et al. Predictors of patient satisfaction with hospital health care. BMC Health Serv Res. 2006;6:102.

11. Gearing RE, Mian I, Barber J, et al. A methodology for conducting retrospective chart review research in child and adolescent psychiatry. $J$ Can Acad Child Adolesc Psychiatry. 2006;15(3):126-134.

12. Ottenbacher KJ, Smith PM, Illig SB, et al. Trends in Length of stay, living setting, functional outcome, and mortality following medical rehabilitation. JAMA. 2004 292:1687-1695.

13. Mallinson TR, Manheim LM, Almagor O, et al. Trends in the supply of inpatient rehabilitation facilities services: 1996 to 2004. Arch Phys Med Rehabil. 2008;89(11):2066-2079.

14. Wilson IB, Cleary PD. Linking clinical variables with health-related quality of life - a conceptual model of patient outcomes. Journal of the American Medical Association. 1995;273:59-65.

15. Cushman LA, Scherer MJ. Measuring the relationship of assistive technology use, functional status over time, and consumer-therapist perceptions of ATs. Assist Technol. 1996;8(2):103-109. 